\title{
WHY CIVILIZATIONS COLLAPSE?
}

\section{Introduction}

One of the questions we can ask ourselves before addressing the analysis of the issue to be dealt with in this work, in which mention will be made of some theories that have sought a satisfactory answer, is what we understand as "collapse".

If we check its definition in a dictionary its first meaning is as follows: "Destruction, ruin of an institution, system, structure, etc." This definition can be considered somewhat vague, and we normally associate "collapse" with something negative. As Middleton pointed out, among the synonyms of this term we find words like "fall", "decline" or "crisis", equally related to a negative or catastrophic situation (2012: 260).

In Demarest's opinion, and thanks to recent studies on possible factors or events that may lead to the end of a civilization, the lack of a clear definition of "collapse" has generated multiple controversies about its interpretation and on some cultural aspects and events. The meaning of similar terms such as "decline", is not as obvious as it might seem, and according to Demarest, this is why many disagreements have arisen on this issue (2001: 105). For Middleton, such misunderstandings originated due to the terminological lack of definition of "collapse", and mainly for two reasons: the clear determination of the consequences that trigger a collapse, and what we understand by such term (2013: 2).

The academic debate around this issue has experienced a resurgence in recent years due to the increased concern about climate change and its potential effects, as well as greater awarenesson the effects that anthropic actions have on the environment.

\section{Different interpretations of "collapse"}

According to Tainter, "collapse" should be understood as a rapid political process of simplification that manifest itself in any complex society and provoke a substantial degradation of their sociopolitical structures (1988: 4).

For Antequera, and taking into consideration Tainter's assessments, one of the main causes of a collapse would be the "energy flow", the amount of energy that a society reaches through different trophic levels and the amount of that energy that comes out. That "energy wlow" must be adequate to allow a proper functioning and development 
of a civilization, and the more complex that civilization is, the greater the energy flow should be (2005). There are two other factors that when they appear simultaneously are essential for a collapse, and they are the following: disturbances and marginal returns. The impact of these two elements will be manifested in the reduction of the possibilities that a society has to increase the complexity of its structures (Antequera, 2005).

Other authors such as Diamond ${ }^{1}$, more influenced in their approaches by other disciplines such as Biology or Ecology, tend to consider a collapse as a consequence derived from a remarkable and sudden population decrease occurred in a society. Despite the obvious differences between the societies of the past and the present, for Diamond, the success or failure of the former was due to similar circumstances to those present in our times (2006: 17).

If the societies of the past disappeared as a result of a collapse, it was due to the gradual degradation of its environment (McAnany \& Yoffee, 2010:4). However, authors like Pomeranz think that despite the undeniable power that the elites of those societies had, they never could cause the destruction of their own environment (McAnany \& Yoffee, 2010: 9). Ponting believes that today's environmental problems are closely related to human actions (1991: 413), and as Diamond, instead of paying attention to the development of various historical events, he focus his studies in the understanding of the "primordial" forces that shape our world, as well as the consequences of human actions on the environment.

The most recent studies carried out on the subject of the collapse of societies have called into question many of the conclusions presented by those researchers who, in one way or another, have followed a line similar to Diamond. This has led to the emergence of two theoretical currents: one that emphasizes the weaknesses of humans to cope successfully with a collapse, and other that reaffirms the value of anthropic actions in their attempt to respond to the consequences of a collapse.

According to Eisenstadt or Tainter, in Antiquity there were no collapses. This opinion is somewhat accepted by McAnany and Yoffee, but they recognise that there were processes that caused major changes in the sociopolitical structures of those societies,

\footnotetext{
${ }^{1}$ For this author, there are five factors that determine the success or failure of a complex society, which are: degree of environmental deterioration, climate change, the presence of hostile cultures, friendly trade associations and possible solutions for the resolution of environmental problems (Goldstein, 2007).
} 
but never triggered a complete and irreversible process of collapse (2010: 6). For Van der Leeuw, any environmental alteration is an essential part of the social and natural process which began in the late Pleistocene (McAnany \& Yoffee, 2010: 6).

However, McAnany and Yoffee do not hesitate to emphasize behaviors that have traditionally been associated with a collapse, such as migrations, changes in livelihood strategies and the use of resources, abandonment of monumentalism and of administrative structures of a certain complexity...etc. All of them, in opinion of both authors, should be identified as adaptive responses to extreme situations. The collapse of the sociopolitical structures of a society would lead to the adoption of organizational models characterized by greater simplicity, and therefore, would require a lower flow energy for its maintenance (McAnany \& Yoffee, 2010: 10).

It is logical to think that the resistance of these collapsing societies is the consequence of environmental changes or wrong decisions taken by its ruling elites, and it should be analyzed taking into consideration their environments. This opinion, formulated by Diamond, it is shared by McAnany and Yoffee, although they do not believe that the rulers of those past societies were responsible for the degradation of their natural environment, as it is known that these societies suffered crises of different impact and they tried to solve them as best as they could (2010:12).

Some researchers who do not share the tenets of geographical determinism, often used to explain why some societies prosper and others fail, consider that the civilizations of Antiquity faced several problems that caused a deterioration of their sociopolitical structures, which they tried to overcome. In Diamond's view, the environmental problems we are experiencing today were certainly much more complex to deal with in the past, especially for those civilizations that were unaware of writing and that could not access to written records that referred to similar situations. The degradation of their environment was a consequence of their eagerness to develop, not because they did so intentionally (2006: 17). Despite these considerations, Diamond believes that the collapse of a society is mainly due to severe environmental disturbances caused by erroneous decisions taken by their ruling elites, as well as lack of criticism by their population.

McAnany and Yoffee believe that the collapse of some societies is due to the selfishness and lack of foresight of their leaders, who instead of preserving their 
environment and the well-being of their community, they only search their own benefit (2010: 8). For Yoffee and others such as Cowgill, "collapse" should not be understood as a process that inevitably leads to the disappearance of a society due to the failure of their sociopolitical structures, because not all civilizations collapse in the same way (1991: 18). Instead, Middleton proposes others such as "transition," "transformation," or "change," which unlike "collapse," are exempt from any negative connotations (2012: 264). According to Middleton's definition of "collapse", it should be understood as a set of different events which cause significant and rapid changes in the sociopolitical structures of a society and in its material culture. In addition, those changes may lead to the dissolution of large state entities, the transformation of their culture and even their definitive disappearance (2012, 267-268).

\section{Approaches to the influence of environmental factors on collapse processes}

To fully understand the possible collapses that could have taken place during Antiquity, it is essential to understand the various approaches formulated to determine to what extent and in what way, environmental factors may be essential to thier genesis and further development. Although archaeologists show great interest in highlighting the importance of human actions as one of the fundamental causes for collapse, Middleton thinks that we should consider environmental factors them more important than they really are (2012: 268). This statement has caused the questioning of many traditionally accepted explanations as well as the possible effects of other factors such as sudden climate changes as triggers for catastrophic events.

Renfrew and Bahn have put forward a series of theories that seek to respond to the phenomenon of collapse. One of the most recurrent is the scarcity of available resources as a result of significant environmental alterations, or due to decisions that ended up being serious mistakes. An example of the latter would be what happened in the Mesopotamian area as a result of excessive irrigation, which would end up degrading the soils and severely affecting agricultural production (2008: 178). Other theories such as those of authors such as Tsonis, de Bruins, McGillivray and Van der Plicht, consider natural disasters as possible triggers, such as the eruption on the island of Thera ${ }^{2}$, which caused the disappearance of the Minoan civilization around $1380 \mathrm{BC}$.

\footnotetext{
${ }^{2}$ As a result of a large and violent volcanic eruption whose dating varies depending on the method used (dating by radiocarbon places it sometime between 1639 and 1616 BC. (Manning, 2006: 565-569),
} 
Tainter echoes other theories that argue that collapses are caused by factors such as the invasion of foreign peoples, conflicts of various types and scope, or even by mystical manifestations (Antequera, 2005). In similar terms A.J. Toynbee considers that all civilizations go through a series of phases throughout their existence, which are: genesis, growth, problems, universal state and disintegration. This statement would later be expanded and reformulated by C. Quigley in The Evolution of Civilizations (1979).

Toynbee believes that collapses are not caused by the degradation of the natural environment, but due to the inability of societies to solve the problems arising from the excessive development of their sociopolitical structures. Collapses would produce a social fracture in these civilizations, in addition to an idealization of the past or the future and the emergence of cultural phenomena such as nihilism or the development of mystical cults that tried to provide a transcendental response (Toynbee, 1961).

In Middleton's view, only explanations based on the incidence of environmental factors should be considered, including the following:

- climatic changes: in the most recent studies it is possible to appreciate a trend that considers this as one of the causes that could cause deep sociopolitical changes that ended up leading to the collapse of some civilizations. According to Weiss, the disappearance of the Tell Leilan ${ }^{3}$ culture in Syria was due to a major change in environmental conditions around 2200 BC. Similarly, Butzer attributes the collapse of the egyptian Old Kingdom ${ }^{4}$ to the progressive and notable decrease in the annual floods of the Nile after 2181 BC. (Renfrew \& Bahn, 2008: 178). According to Middleton, thanks to the evidence we currently

\footnotetext{
according to archaeological evidence, the destruction of much of the island of Thera (now Santorini) occurred between 1530 and 1500 BC (Pollinger-Foster \& Ritner, 1996: 1-14). It was one of the most important natural disasters in the Aegean during the Bronze Age. The eruption caused important climatic changes in the Eastern Mediterranean area (Lilley, 2006) and by extension in the rest of the Earth (Vergano, 2006). Some researchers believe that this event could give rise to the myth of Atlantis (Oppenheimer, 2003).

${ }^{3}$ Archaeological site located in present-day Syria. The oldest remains of human occupation date back to the 5th millennium BC. Around 2600 BC, a city called Shekhna arose, which would end up being annexed to the Akkadian Empire between 2300-2200 BC. Barely a century later it would be abandoned due to a severe drought that modified the climatic conditions of the region. According to archaeological evidence, the population was gradually abandoning it until 2140 BC. moment in which no human occupation is attested.

${ }^{4}$ During the V and VI Dynasties the collapse of this first Egyptian Empire occurred due, among other sociopolitical causes, to a great drought that occurred between 2200 and 2150 BC that significantly reduced the volume of the Nile floods. In addition, for a few decades before they had been suffering major famines that caused numerous disturbances that weakened the authority of the pharaohs.
} 
have, it is possible to determine that these collapses were due to rapid and significant climatic changes that provoked a series of adaptive responses (2012: 270). Riechmann goes even deeper questioning if these climatic alterations and the sociopolitical modifications arising from them could be considered as a reason to provoke the collapse of a civilization, which in his opinion cannot be answered using climatic or economic patterns (2007: 75).

- ecocides and inappropriate decision-making: according to Broswimmer, "ecocide" should be understood as a set of intentional actions that seek to cause the degradation of an ecosystem through the use of chemical compounds or weapons of mass destruction that end up causing natural disasters (López, 2014: 17). This definition differs from Middleton's, but essentially both refer to human-caused environmental degradation. Based on a series of archaeological evidence that Middleton considers conclusive, he has tried to demonstrate the ability of all societies to alter their environments (2012: 270). Lack of adaptation to the new conditions caused by environmental changes will inevitably lead to collapse, a fact that Middleton even considers "beneficial" since they cause a cultural and environmental "reset" that can lead to the emergence of new societies (2012: 271).

- catastrophic events: natural catastrophes can trigger sociopolitical changes that lead to the end of a civilization (Middleton, 2012: 271). Tainter only considers phenomena such as earthquakes, volcanic eruptions or epidemic plagues (Antequera, 2005), as well as tidal waves such as the one caused by the violent eruption that wiped out much of the island of Thera. Theories based on the incidence of natural disasters have found certain reluctance among the academic community to be considered as a probable cause of the collapse of complex societies. Despite this, it is possible to find several historical examples of the aforementioned, such as the end of the Minoan culture in Crete, although there are others that seem to invalidate them, such as the destruction of the cities of Pompeii and Herculaneum as a result of the eruption of Vesuvius in 79 AD, which obviously did not produce the fall of Rome. The effects of a natural catastrophe do not affect in the same way to all civilizations, but as Middleton indicates when referring to the views of McAnany and Yoffee, the consequences 
are essentially the same in all of them: some societies managed to adapt while others disappeared (2012: 273).

\section{Can collapses be avoided?}

Throughout history, various complex societies have emerged that ended up collapsing without any environmental cause or other exogenous factors that could have caused their end, although in some cases it was caused by themselves. An example of this would be, according to Diamond and based on Flenley, the Rapa Nui civilization, which caused an involuntary ecocide (2005: 26). However, the concepts of "resistance" and "adaptability" formulated by McAnany and Yoffee can be a good example of the efforts of many complex societies of the past to avoid their disappearance.

Many of Tainter's conclusions have been collected by R. Duran and L. Gonzalez in their work In the spiral of energy (2014). In an interview in April 2015 ${ }^{5}$, Gonzalez stated what are the most significant postulates of Tainter, which are:

- both energy and environmental factors are essential for the development of societies, but they are solely responsible for their success or failure.

- human beings have developed two different models of civilization: one characterized by a more egalitarian and peaceful society without developed hierarchical structures, which have a more respectful relationship with their environment; and another whose hallmarks are greater social complexity, much more violent and hierarchical, whose interaction with the environment is far from harmonious. According to Tainter, this second model ended up giving rise to today's capitalist society.

In that interview, Gonzalez expressed his belief in the inevitability of the decline and subsequent collapse of industrial society, and that the new civilization that arises from the latter must be based on agriculture, the use of renewable energies and a clear determination of environmental limits. According to Ibanez, the increase in the sociopolitical complexity of many civilizations of the past led them to their own destruction as they were not sustainable (2014). In 2011 Tainter affirmed that the awareness of sustainability arises in those societies that, due to certain circumstances,

\footnotetext{
${ }^{5}$ http://www.utopiacontagiosa.org/2015/04/16/en-la-espiral-de-la-energia-entrevista-con-luisgonzalez-ecologistas-en-accion-13/ (accessed June 2017)
} 
are forced to seek solutions to solve their problems, cementing their success or failure in their ability to face them. In Tainter's opinion, the societies of the past that managed to endure did so because they knew how to successfully deal with their economic problems ${ }^{6}$.

If we accept Middleton's definition of "collapse", which was elaborated by the aforementioned author based on various contributions from other disciplines such as History, Archeology or Biology, in order to strip it of any negative connotation and conceive it as the decline and end of a complex society, instead he proposes to define it as a process of change produced by significant environmental alterations to which societies must adapt in the best possible way, and assume the changes that these may produce. Likewise, the sustainability of a certain complex society does not depend only on its members (although certain decisions of its ruling elites are important because they can produce imbalances), since the incidence of natural factors plays an important role in their evolution.

\section{Conclusions}

In general terms, it can be affirmed that the environmental effects that affected societies in the past are, essentially, the same ones we are facing today, although it is significant that human beings have begun to become aware that their actions can cause profound modifications in their natural environment, many of them a consequence of their needs, which largely depend on the level of social complexity. Likewise, it is possible to think that human societies have only adapted to their environment when they have been deprived of other alternatives, which forces them to undertake structural modifications to solve their problems.

According to a mathematical prediction model commissioned by NASA to the Goddard Space Flight Center $^{7}$, called HANDY ${ }^{8}$, five determining factors have been determined for the collapse of a civilization, which are: climate, population, water resources,

\footnotetext{
${ }^{6}$ https://dedona.wordpress.com/2011/03/11/entrevista-con-joseph-tainter-autor-de-el-colapso-desociedades-complejas/ (accessed June2017)

${ }^{7}$ Research laboratory dependent on NASA founded on May 1, 1959 as the first space flight center whose headquarters are in Greenbelt (Maryland). Among its tasks are the study of the Universe and the development of scientific satellites. It is named after Robert H. Goddard (1882-1945), one of the early pioneers in rocket propulsion.

${ }^{8}$ Human and nature dynamics (HANDY). It is an experimental model based on the interaction of human beings with their environment, whose purpose is the long-term prediction of possible sociopolitical collapses due to the overexploitation of available resources.
} 
agriculture and energy. When these five elements converge simultaneously, the "perfect collapse" occurs, causing an overexploitation of resources as a result of the degradation of economic structures and a greater social hierarchy that will increase inequalities among the population.

Therefore, it would be essential to have as much knowledge as possible about how those societies that preceded us faced a series of problems that seem to enjoy the same validity as they once had, in addition to promoting greater awareness of the effect that anthropic actions have on the environment, since many of the factors that could lead to the collapse of our current society, in the same way that it happened with others in the past, is largely a consequence of our own actions.

\section{BIBLIOGRAPHY AND INTERNET SOURCES}

ANTEQUERA, J. (2005) El potencial de sostenibilidad de los asentamientos humanos http://www.ordenjuridico.gob.mx/Publicaciones/CDs2010/CDMetropolitano/pdf/DOC0 1.pdf (accessed mayo 2017)

BAHN, P.; RENFREW, C. (eds.2008). Arqueología. Conceptos clave. Madrid: Ediciones Akal.

BRUINS, H.J. et al. (2009) The Minoan Santorini eruption and Tsunami deposits in Palaikastro (Crete), Radiocarbon 51.2, pp.397-411.

DEBER-JALKOTZI, S. (2010). "Decline, Destruction, Aftermath" in SHELMERDINE, C.W. (ed.) The Cambridge Companion to the Aegean Bronze Age. Cambridge: Cambridge University Press, pp. 387-415.

DELGADO, S.; ROSAS, M. (2012). De colapsos y continuidades. Una valoración conceptual del estudio de sociedades en transición, Sostenible 13, pp. 13-29.

DEMAREST, A. (2001) Climatic change and the Classic Maya collapse: the return of catastrophism, Latin American Antiquity 12, pp. 105-107.

DIAMOND, J. (2006) Colapso. Por qué unas sociedades perduran y otras desaparecen. Barcelona: Random House Mondadori 
FERNANDEZ, R.; GONZALEZ, L. (2014) En la espiral de la energía (2.vols.), Madrid: Libros en Acción

vol.1: http://www.ecologistasenaccion.org/IMG/pdf/en-la-espiral-de-la-energia_vol1.pdf (accessed June 2017)

vol.2: http://www.ecologistasenaccion.org/IMG/pdf/en-la-espiral-de-la-energia_vol2.pdf (accessed June 2017)

IBANEZ, I. (2014) La decadencia de las civilizaciones y su complejidad, http://www.madrimasd.org/blogs/universo/2014/11/01/145559 (accessed June 2017)

KAUFMAN, H. (1988). "The collapse of ancient states and civilizations as an organizational problem" in YOFFEE, N.; COWGILL, G.L. (eds). Collapse of Ancient States and Civilizations. Tucson: University of Arizona Press, pp. 219-235.

LÓPEZ, S. (2014) 100 (+1) reseñas, Rebelion. http://www.rebelion.org/docs/50842.pdf (accessed June 2017).

McANANY, P.; YOFFEE, N. (2010). "1. Why We Question Collapse and Study Human Resilience, Ecological Vulnerability, and the Aftermath of Empire" in McANANY, P.; YOFFEE, N. (eds.) Questioning Collapse. Human Resilience, Ecological Vulnerability, and the Aftermath of Empire. Cambridge: Cambridge University Press, pp. 1-17.

MIDDLETON, G.D. (2012) Nothing last Forever: Environmental Discourses on the Collapse of Past Societies, Journal of Archaeological Research 20 (3), pp. 257-307. (2013) That old devil called collapse, E-International Relations http://www.e-ir.info/2013/02/06/that-old-devil-called-collapse (accessed June 2017) MOTESHARREI, S.; RIVAS, J; KALNAY, E. (2014) Human and nature dynamics (HANDY): Modeling inequality and use of resources in the collapse or sustainability of societies, Ecological Economics, vol.101, pp. 90-102. http://www.sciencedirect.com/science/article/pii/S0921800914000615\# (accessed June 2017)

NASA's Goddard Space Flight Center: https://www.nasa.gov/goddard (accessed June 2017) 
NUWER, R (04/18/2017) "How Western civilisation could collapse"; BBC.com: http://www.bbc.com/future/story/20170418-how-western-civilisation-could-collapse (accessed June 2017)

PONTING, C. (1991). A Green History Of The World: The Environment and the Collapse of Great Civilizations. New York: Penguin Books.

RIECHMANN, J. (2007) Calentamiento climático: ¿cómo se calcula su impacto?, Papeles de cuestiones internacionales $n^{\circ} 98$, pp. 63-80.

TAINTER, J. (1988). The Collapse of Complex Societies. Cambridge: Cambridge University Press.

TOYNBEE, A.J. (1995) Estudio de la Historia (edición completa); Barcelona: Altaya TSONIS, A. et al. (2010) Climate Change and the Demise of Minoan Civilization, Climate of the Past Discussions 6 (4), pp. 525-530.

YOFFEE, N.; COWGILL, L. (1991) The Collapse of Ancient States and Civilizations. Tucson: The University of Arizona Press

ZARZALEJOS PRIETO, M. (2010) "La Creta minoica y el sistema palacial”, in ZARZALEJOS PRITO, M.; GUIRAL PELEGRÍN, C.; SAN NICOLÁS PEDRAZ, Ma P. Historia de la cultura material del Mundo Clásico, Madrid: UNED, pp. 45-71. 